\title{
MEDICAL EXPERIMENTATION CONCERNING CHEMICAL AND BIOLOGICAL WEAPONS FOR MASS DESTRUCTION
}

\author{
Erwin Deutsch*
}

This article is the text of a speech originally presented at the Second World Conference on Medical Ethics at Gijon, Spain, on 2 October 2002 under the title "Medical Experimentation Concerning Chemical and Biological Weapons for Mass Destruction: Clinical Design for New Smallpox Vaccines: Ethical and Legal Aspects". Experimentation on vaccines such as smallpox is subject to the usual ethical rules such as the need for informed consent. However, the participants will not often be at risk of catching the disease but expose themselves by taking part in the experimentation. Professor Deutsch explores the implications of this, including the position of vulnerable groups such as children, those with mental handicaps, and those acting under orders such as the military, the police and fire officers.

\section{INTRODUCTION}

One of the very first cases reporting medical experimentation concerns vaccine, to be more specific, vaccine against smallpox. Voltaire reports in his Lettres Anglaises about medical experimentation on prisoners in London. ${ }^{1}$ The British envoy to Turkey had reported a tribal custom from the Caucasus Mountains where small children were brought into bleeding contact with a person suffering from smallpox. The result was that the children never developed smallpox. The custom was supposedly picked up from the Arabs, though this has never been confirmed. In London, inmates of the Newgate Prison who had been condemned to death were given the chance to participate in a trial with what is now known as smallpox virus. All participants survived and were released. As a result of that trial the inoculation against smallpox became widespread in England. Voltaire contrasts this beneficial development with the rigid French attitude where the court in Paris had recently disallowed similar experimentation on humans as assault and battery.

* Professor Emeritus, University of Göttingen.

1 Fernand Massé (ed) Lettres Anglaises (Pauvert, 1964) 62. 
The biggest medical trial of all times concerned a vaccination as well. This was the Salk-Poliovaccine that was tried out on a few hundred thousand children in the United States in the mid-fifties. There, half of the children were given the vaccine and the other half acted as controls. Many parents cheated the system by enrolling their children in different locations for the trial, hoping to be at least once in the verum-group. The experimentation established without doubt the efficacy of the Salkvaccine against polio.

Now the great curse of yesterday returns under the guise of a possible terrorist attack. We are reminded of the attack on the Genuese garrisons on the Crimea in the Middle Ages, to be specific in the fourteenth century, where the bodies of pestilence victims were thrown over the barricades into the fortified cities. All this resulted in the flight of the defenders taking with them the pestilence to Europe with terrible results.

\section{GENERAL RULES OF EXPERIMENTATION}

For new smallpox vaccines the normal rules of medical experimentation apply, but at the outset there has to be a stated special feature of the trial: the experimental subjects are often not at immediate risk of catching the smallpox. On the contrary, they are used to establish whether the vaccine is safe and effective. As far as effectiveness is concerned, the trial has some analogy to hyper-immunisation of volunteers to produce anti-bodies against an illness they have not contracted but that they have been infected with. From there we know that adequate information and consent in writing has to be given. Moreover the participants have to get compensation for untoward damage suffered while an experimental subject.

According to the Declaration of Helsinki ${ }^{2}$ and generally accepted legal rules which appear in pharmaceutical statutes as well as in court cases, it is necessary that the predictable risks and burdens are adequate in comparison with the foreseeable benefits to the subjects or to others. In other words, the experimentation has to be medically acceptable as far as the human subjects are concerned. The medical acceptability has to be established according to the prevailing opinion in scientific circles, but medical acceptability means as well that the volunteers believe the risks and burdens to be tolerable. This will be established mostly by the information given in connection with informed consent. But the general question of medical acceptability is not one that could be decided solely by the scientific community but has to take into account the understanding and expectation of the experimental subjects as a group.

Another equally important requirement is informed consent. The volunteers should be informed about the aims, methods, benefits and risks of the study as well as the discomfort it might entail. Experimentation on unknowing subjects has always been illegal and has given rise to criminal procedures. The consent following the information has to be freely given. There should be no

2 World Medical Association Declaration of Helsinki: Ethical Principles for Medical Research Involving Human Subjects (Edinburgh, 2000). 
duress, intimidation or deceit. Taking part in the drug trial is reserved for volunteers: volunteers are only persons that can express their free will, chosen upon full information. Consent given under intimidation or deceit is not valid and gives rise to criminal and civil legal action. There is still some debate whether soldiers under command of their officers have to give their informed consent or are required, at least after some information, to participate. That problem will be dealt with later on.

There is some uncertainty whether the informed consent should be given in writing, be it that the information is contained in a standard form or the consent is written out by the participant. Unless otherwise required by the law, informed consent has no formal prerequisites. To use written forms ensures identical information and establishes proof of the actual giving of the consent. Anyway, the consent has to be given in absolute freedom. This implies that the experimental subject can withdraw the informed consent at any time without giving reasons.

There should be no experimentation on members of so-called "vulnerable groups". Such groups are children and members of some special organisations with an honour code, for example, police or firemen. Under exceptional circumstances there can be reason to allow medical experimentation on vulnerable groups. The general ban on medical trials is based on their very vulnerability, for example, that the participants are not free to give their consent. Children are usually too small or too dependent on their parents. Members of a group with an honour code might be bound by that code to take part together with their colleagues. But where an illness concerns mostly members of the group, for example, typical children's ailments, medical experimentation on children is acceptable. One of the reasons is that the trial cannot be performed on consenting adults. But there have to be safeguards. Whether it is really necessary to perform the trial on children has to be debated and approved by a committee, usually an ethics committee, with members who are familiar with the treatment of children. There is still the unsolved problem, whether a clinical trial on children can make use of a control group. Here it is necessary to differentiate. The children in the control group should not be subjected to more than minimal participation. There should be no longterm or repetitive measures performed on them. Harm and inconvenience should be minimal.

There is still some disagreement whether the experimental subjects have to be told who initiated the trials and paid for them. There has been some discussion whether a trial at the Max-PlanckInstitute for Psychiatry in Munich on easily alarmed patients should have included the information that it was paid for by the civil defence authorities. From the point of view that, in medical experimentation, information has to be complete, the sponsor should be included.

At least there can be some financial or other compensation for taking part in the experimentation. Anyway, an innocent victim from the experiment should be compensated without having to establish negligence or fault. The legal basis for financial compensation of loss is obvious: the experimental subjects sacrifice their health for the common welfare. 


\section{MEDICAL SAFETY}

The tests concerning the safety of the vaccine are sometimes referred to as "phase I" of a clinical trial. It is the first step into the unknown territory of the new drug. One of the starting points of medical experimentation is that the new drug poses little risk for the volunteer. This is especially true if healthy volunteers are used for testing vaccines. It is particularly the case if the vaccine should work against an illness where there is no cure. Some recent cases concern the question of safety.

\section{A The Kennedy-Krieger Lead-abatement Study ${ }^{3}$}

The case concerns the effectiveness of three different methods of reducing environmental lead in older homes. Environmental lead levels were measured using different methods, one standard and the other experimental. Moreover, blood lead levels of young children living in the homes were monitored. The blood lead levels declined in nearly all the children involved in the study. Two sets of parents brought suit claiming that they were not informed that lead remained a potential hazard in the home and that high dust levels were found in the home, even when their child's blood-leadlevels rose. It is suspected that it was a house that acted as a "control". The Baltimore City County Court dismissed the law suits summarily. The Maryland Court of Appeals reversed the lower court; it ordered that the law suits should proceed to trial, and stated that a parent cannot consent to a child's participation in non-therapeutic research in which there is any risk of injury or damage to the child's health.

\section{B Stateville Prison in Illinois}

During the Second World War, there were clinical trials with malaria in Illinois. The inmates were asked to participate, were not promised an early release but were closely monitored. There were no cases of death. It appears that the volunteers were finally released early.

\section{EFFICACY}

The test whether a drug is efficient is sometimes called "phase III" study. Usually it is a clinically controlled study with at least one group getting the verum and another one serving as a control. The real problem of vaccine experimentation exists in this field of efficacy. A good many cases have touched on this.

\section{A Bailey v Mandel ${ }^{4}$}

In a prison in Maryland, experimentations were going on to prevent or treat typhus, malaria, cholera and influenza. The participants at the experimentation ward were treated much better than

3 Robert Nelson "Non-therapeutic Research, Minimal Risk and the Kennedy-Krieger-Lead-abatement Study" [2001] IRB 7.

4 George J Annas Informed Consent to Human Experimentation (Ballinger, Cambridge MA, 1976) 144. 
the rest of the inmates: they had quiet rooms, air conditioning, TV, and got at least two dollars a day. The case was settled out of court.

\section{B Somatic Gene Therapy}

The trial concerned the treatment of a rare disease: OTO-deficiency which appears in a serious form in small children and in a more benign version at a later age. Following the advice of an ethical expert, the experimental somatic gene therapy was tried out on an eighteen-year old and not on small children. The reason was that the grown-ups could give their informed consent personally. The subject died. The case against the hospital and the ethical advisor as well is based on the assumption that a greater risk of a minor illness should not have been run just in order to get the personal consent. The case has not been decided yet.

\section{Polio-Salk-Vaccine Trial in 1955}

The first vaccine against polio was tried out on many children. There are reports claiming that a few hundred thousand children took part. As discussed above, they were divided into two groups. One group got the vaccine, the other the placebo. It is also reported that many parents cheated or at least tried to cheat the system by enrolling their children in more than one trial which took place all over the country.

The test whether a vaccine is effective poses tricky ethical and legal questions. The tests are not outlawed by themselves because the experimental subjects lack an illness to be treated or are in no immediate danger. Trials to keep infections, especially epidemics, at bay are allowed. But on the other hand the health and well-being of the experimental subject comes into focus. If there is more than a minimal chance that the experimental subject, especially the members of a control group, can catch the agent, then the experimentation should not be allowed. Even the informed consent of the patient does not allow that person to be put in such a mortal danger. In this instance, the credo of the controlled clinical trial, using test groups and placebo groups, should be questioned. Maybe the population in general might work as a control.

Research subjects obeying orders pose a special problem. Usually these are military personnel, but members of some other professions as well, for example, hospital personnel. Consent is superfluous if you are under duty. The question is whether the person at risk should be informed. In the Thorathast case during the Second World War at Heidelberg University Hospital and in the Desert Storm exception to the use of investigational new drugs, it was held that no information had to be given to the soldiers. This should be questioned, not so much on the basis of consent, but to keep the people informed about their risk and the possibility of getting compensation.

\section{INFORMED CONSENT}

Though normally information precedes consent and most court cases for lack of informed consent are based on no or insufficient information, consent is the main legal basis for experimentation. Consent should be given by the experimental subject, as already stated, and has to 
be completely free without coercion or deceit. The consent relates back to the information and does not go further than what the experimentational subject has heard or read. The consent has two legal sides. The first one is allowing the invasion of the person. That way assault and battery in its different forms are excluded because of justification by consent. The other side of the coin is that the consenting subject normally bears the risk of damage to health. It is a different story if there has been negligence or if compensation is given, but normally the experimental subject feels the consequences.

Information that leads to consent has to be given completely and exhaustively. The subject has to know what the experimentation entails to the person. Moreover, the subject has to be told about the duration, the discomforts, the risks and probable benefits. On the basis of that information the experimental subject gives the consent:

\section{A United States $v$ Rose $^{5}$}

The accused had provided a KZ with viruses and vaccines for experimental purposes. Two groups were constituted, one had been vaccinated, the other one not. There were probably 729 probands and at least 154 deaths.

\section{B United States $v$ Stanley}

A sergeant of the American Army volunteered for a programme concerning protective clothes against chemical warfare. Without his knowledge he was administered LSD which led to hallucinations and loss of memory.

\section{Halushka v University of Saskatchewan ${ }^{7}$}

For fifty dollars a student had participated in an experimentation concerning general anaesthaesia. He had been told that a new medication would be tried out on him and that a catheter would be used. He had stated in writing that he had been fully informed and had absolved the University and the doctors from all responsibility. During the experimentation the catheter reached the heart and it stopped beating. The student was finally saved and sued the University and succeeded in the Court of Appeal. One reason given was that he had not been fully informed about the procedure of the catheter and the danger of the experimentation. The disclaimer was void.

5 Trial of War-Criminals before the Nuremberg Military Tribunals, Vol 2, (USGPO, Washington DC, 19491953) 264.

$6 \quad$ (1987) $107 \mathrm{~S} \mathrm{Ct} 3054$.

7 (1965) 52 WWR 608 (Saskatchewan Court of Appeal). 


\section{VULNERABLE GROUPS}

Special care has to be given to the members of so-called vulnerable groups. These groups are vulnerable because their understanding of the procedure and the danger or the formation of a free will can be questioned. These groups consist of children, the mentally handicapped and cohesive groups like the military, the police and firemen where a single member might not dare to differ from the others. Usually clinical trials with members of one of these groups are only permissible if the group itself is in danger. Contagious diseases that affect children can sometimes be treated only in children and a vaccine against the illness has to be tried out on children. Whether patients who are in hospital because of some treatment unconnected with the trial can be used is still hotly debated. Mostly it is not regarded as impermissible, but there is special care required in getting informed consent.

\section{A Weiss v Solomon ${ }^{8}$}

At the Jewish General Hospital in Québec a patient had had surgery on his eyes. The doctor asked him to take part in an experimentation where the efficacy of opthalmological drops should be tested. The hospital's research committee had approved of the patient's participation, but he died of a heart attack. The case of the widow and the patient's children against the doctor and the hospital was successful. The hospital was liable among other reasons because the ethics committee had not insisted on fully informed consent about the risks and had allowed the experimentation to take place in a room that was not equipped to deal with heart attacks. Moreover, the patient who had had a history of heart trouble should have been excluded.

\section{$B$ Neilson $v$ The Regents of the University of California ${ }^{9}$}

The suit was brought by an attorney who had been a member of the Institutional Review Board of the University. He asked for a temporary injunction to prohibit non-therapeutic experiments on children. The trial concerned asthma. Two groups of children were to be compared, one group had parents with asthma, the other had not. The children would get veni-puncture four times a year and later on injections under the skin. The parents were promised $\$ 300$ per participant. The court did not grant the injunction because of very narrow grounds. It looked at the California statute against cruelty against children and found that it was not applicable.

\section{CONTROLS, PLACEBOS AND RANDOMISATION}

Medical research is most persuasive if performed by comparison. This is true for inoculations as well. Using different groups in vaccine trials, one acting as control group, has been rarely attempted and has never been fully accepted. Trials with vaccina-antigene and MVA vaccine in

8 (1989) 48 CCLT 280 (Cour Supérieur de Québec).

9 (1975) Superior Court of California. 
1959 and 1971 against smallpox did not use a control group. The trial in the Netherlands in 1962 with combined active-passive vaccination suffered because the homogenity of the group was not established. There had been experimental subjects who had been inoculated earlier.

The use of placebos in vaccination trials poses serious problems. As long as different vaccines are tested against each other there is the usual uncertainty that justifies medical research. But knowingly to let a group of people face the real danger of contracting the disease without any protection has been held unethical, illegal, even criminal. Informed consent by volunteers does not allow the immediate infection of the research subject as was done in the most recent vaccine trial against malaria on seventy volunteers in Oxford. Here the participants were given five bites from heavily infectious mosquitoes. The vaccine is now being tested in the Gambia on 360 adults, half will be given the new vaccine and the other half a rabies shot which has the virtue of providing useful protection against the disease endemic in the area, rather than being a mere placebo. ${ }^{10}$ Naturally, as regards malaria, it is a placebo.

The uses of placebo have been limited in the most recent version of the Declaration of Helsinki by the World Medical Association. ${ }^{11}$ The use of placebo is allowed where no proven prophylactic, diagnostic or therapeutic methods exist. This rule led to a battle royal between the American medical establishment and the World Medical Association. There is now a "Note of Clarification" by the governing body of the World Medical Association that a placebo controlled trial may be ethically acceptable when there is compelling, scientifically sound methodological reason to compare an intervention to a placebo or if the intervention being studied is of a minor condition and the trial will expose those who received a placebo to no additional risk of serious or irreversible harm. The smallpox vaccine trials touch on that issue.

Randomisation $^{12}$ is used to avoid freak results and leads to more representative groups. In vaccine trials the number of participants has to be very high. Because of the large group of population involved there is very little room for randomisation.

10 "Malaria vaccine is being tested in the Gambia" (24 August 2002) The Economist 60

11 World Medical Association Declaration of Helsinki: Ethical Principles for Medical Research Involving Human Subjects (Edinburgh, 2000) C 29.

12 "Randomisation" means the partition of research subjects into different groups according to a complicated formula. This is already complicated in a trial of a few hundred volunteers. It is nearly impossible to administer to a group of hundred thousands or millions of persons. Moreover since the control group might get a placebo, there is a danger of large-scale cheating the system as was done with the Salk-polio vaccine trial in the 1950s in the United States, where parents enrolled their children at more than one place to be at least once in the test group. 


\section{LIABILITY AND COMPENSATION}

If in performing the experimentation or in any other way connected with it there has been malpractice, there should be liability because of negligence. ${ }^{13}$ Negligence implies that a duty of care has not been exercised. The duty is in the first instance an obligation of the doctor who performs the trial, but there are secondary duties to be performed by an institutional review board or the Government. If there has been no negligence, there could be some other form of a case for compensation. Compensation does not give full damages, but somehow compensates the innocent victim. For example if the volunteer has given up a right or provided dangerous services. Compensation is always due if the experimental subject had not been asked to give informed consent, especially if these are soldiers on military orders. But in some countries there are more general rules concerning objective liability or compensation for the risk that materialises in clinical experimentation. Two cases might illustrate that.

\section{A German Supreme Court ${ }^{14}$}

A soldier who had suffered an aneurysm on his left leg had been transferred for treatment to the Heidelberg University Hospital. There he underwent an arteriography where radioactive thorathast was used. The main purpose of using thorathast was experimental, because the doubts about the safety of thorathast might be dispelled by using it as often as possible. The soldier suffered cirrhosis of the liver as a consequence. The German Supreme Court stated that the case concerned mostly experimentation, but the soldier nevertheless was under orders to participate. Since there was no informed consent, the risk of the experimentation was borne by the government which ordered the soldier to obey. Compensation was granted.

\section{B Berkovitz v US Supreme Court ${ }^{15}$}

A two month old infant was given oral polio-vaccine manufactured by the Lederle laboratory. Within 2 months he contracted a severe case of polio. There could be liability of the Federal Government if there was failure to exercise or perform a discretionary function or duty on the part of the Federal Agency or an employee of the Government. It was claimed that the NIH division of biological standards should not have licensed Lederle to produce. The Court of Appeal had dismissed the case. The Supreme Court reversed. It was possible that the conduct challenged did not involve a permissible exercise of policy discretion. If this was the case, then the act of the Federal Government was improper.

13 This is subject to legislation to the contrary, as with the accident compensation scheme in New Zealand. See the Injury Prevention, Rehabilitation, and Compensation Act 2001.

14 (1956) BGHZ 20, 61.

15 (1988) 486 US 531. 


\section{SPECIAL SITUATIONS AND WAR}

The rule of law and the normal ethics considerations apply to normal conditions. In case there are abnormal conditions, there is some relaxation of the rules, but by no means a total disregard. A good case in point is the following court case:

\section{A Doe v Sullivan ${ }^{16}$}

During Operation Desert Storm, the main part of the war between the United States and Iraq, there was the danger that the other side might use chemical or biological weapons. Therefore the Pentagon asked the Federal Drug Agency (FDA) to use non-approved drugs and vaccines even without knowledge of the soldiers in the theatre of war. Military necessity was given as the reason. The FDA granted the exception because there was a war going on and the immediate danger for the troups was recognisable. The case came to court, but in two instances the handling of the case by the FDA was upheld for different reasons.

The war against terror creates another special situation. There is the actual danger of using viruses for terrorist purposes. Therefore persons who will come into contact with contagious diseases might be obliged to be inoculated. This concerns especially workers in hospitals and other health institutions who might get into contact with infected persons early on. Wherever there is the opportunity of developing a new vaccine against smallpox with no known side-effects, experimentation should be permissible. Because of the large number of persons concerned, there could be two groups, one inoculated with the usual vaccine acting as controls and the other getting the new vaccine.

The inoculation against smallpox started the debate about human experimentation. More than two hundred years later humanity faces the same old problem. But this time the possible aggressor is not nature itself, but humans.

16 (1991) 756 F Supp 12; (1991) F2d 1370. 